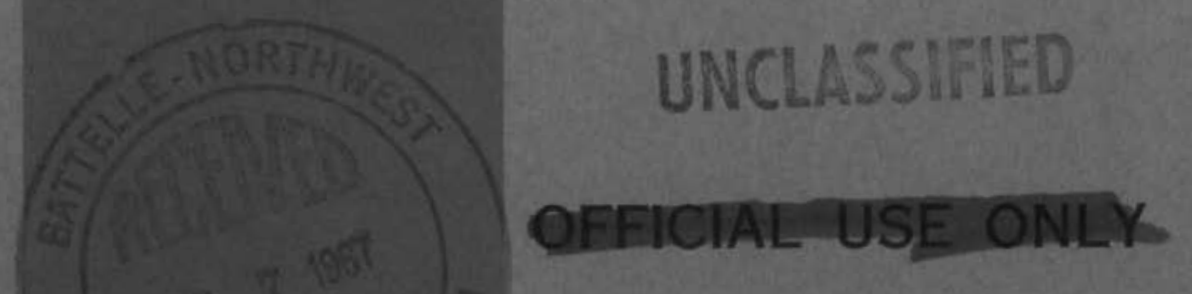

BNWL-445

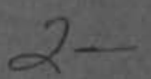

\title{
PACIFIC NORTHWEST LABORATORY MONTHLY ACTIVITIES REPORT FOR APRIL 1967
}

\section{DEVELOPMENT}

REPORT

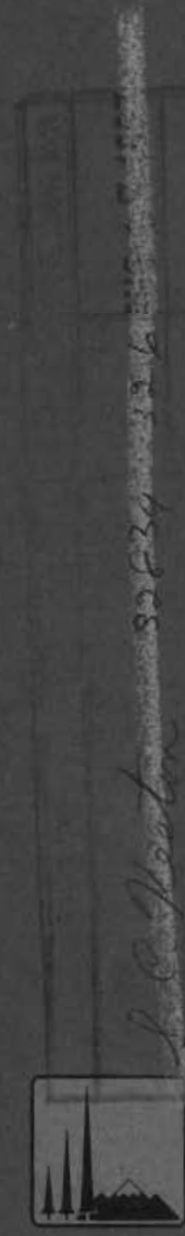

\author{
DIVISION \\ OF \\ BIOLOGY AND MEDICINE \\ PROGRAMS
}

MAY 1967

\section{BAtTELLENN}

BATTELLE MEMORIAL INSTITUTE / PACIFIC NORTHWEST LABORATORY

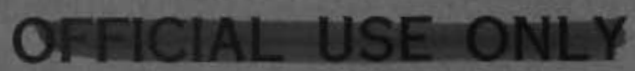




\title{
INFORMATION CONCERNING USE OF THIS REPORT
}

\section{PATENT STATUS}

This document copy, since it is transmitted in advance of patent clearance, is made available in confidence solely for use in performance of work under contracts with the U. S. Alomic Energy Commission. This document is not to be published nor its contents otherwise disseminated or used for purposes other than specified above before palent approval for such ralease or use has been secured, upon request, from the Chief. Chicago Patent Group, U. S. Atomic Energy Commission. 9800 So. Cass Ave., Argonne, llitinois.

\section{PRELIMINARY REPORT}

This report contains information of a preliminary nature prepared in the sourse of work under Atomic Energy Commission Contract AT(45-1)-1830. This information is subject to correction or modificotion upon the collection and evaluation of additional data.

\section{LEG.AL NOTICE}

This report was prepared as an account of Government sponsored work. Neither the United States, nor the Commission, nor any person acting on behalf of the Commission:

A. Makes any warranty or representation, expressed or implied, with respect to the accuracy, completeness, or usefulness of the information contained in this report, or that the use of any information. apporatus, method, or process disclosed in this report may not infringe privalely owned rights; of

8. Assumes any liabilities with respect to the use of, of for damages cesulting from the use of any information, apparatus, method, or process disclosed in this report.

As used in the above, "person acting on behalf of the Commission" includes any employee or contractor of the Commission, or employee of such controctor, to the extent that such employee or contractor of the Commissios, or employee of such contractor prepares, disseminates, or provides access 10. any information pursuant to his employment or contract with the Commission, or his employment with such contractor.

\author{
PACIFIC NORTHWEST LABORATORY \\ RICHLAND, WASHINGTON \\ operated by \\ BATTELLE MEMORIAL INSTITUTE \\ for the \\ UNITED STATES ATOMIC ENERGY COMMISSION UNDER CONTRACT AT(45-1)-1830
}

PRINTED BY/FOR THE U.S. ATOMIC ENERGY COMMISSION 


\title{
UNGUSSPED
}

\section{3}

$$
\begin{gathered}
\text { BNWL- } 445 \\
\text { UC- } 48
\end{gathered}
$$

Biology and Medicine (Special Distribution)

PACIFIC NORTHWEST LABORATORY MONTHLY ACTIVITIES REPORT APRIL 1967

\author{
Division \\ of \\ Biology and Medicine \\ Programs \\ by the \\ Staff of Battelle-Northwest \\ S. L. Fawcett, Director
}

May, 1967

PACIFIC NORTHWEST LABORATORY RICHLAND, WASHINGTON 


\section{PACIFIC NORTHWEST LABORATORY}

MONTHLY ACTIVITIES REPORT

APRIL 1967

AEC DIVISION OF BIOLOGY AND MEDICINE PROGRAMS - R. S. PAUL

$\underline{\text { RADIATION EFFECTS - GENERAL }}$

Mechanism and Treatment of Gastrointestinal Radiation

Effects - M. F. Sullivan

Rats were surgically prepared with dual biliary cannulae that drained bile into the lumen of the duodenum and pancreatic secretion externally. Animals so treated were exposed to $1250 \mathrm{R}$ abdominal X-irradiation and killed at daily intervals. Results should indicate whether pancreatic secretion, like bile, is harmful to the irradiated mucosa. Histologic evaluation is not yet completed.

Cannulation of the mesenteric lymph duct allowed collections of lymph drained from the small intestine for periods extending up to 19 days. The average flow in a single rat over 16 consecutive days was $26 \mathrm{ml}$. A comparison is now being made of the lymph volume and several constituents of lymph between irradiated and non-irradiated rats.

Results obtained in vitro on the effect of radiation or bile salts on the electrogenic transport process in the rat intestine indicate that there are two different processes responsible for transport. These are not affected to the same degree by either bile or radiation. In the absence of bile the ileum develops a higher diffusion potential and transports electrolytes more readily than when bile is present. After exposure to radiation, or when bile salts are present, both diffusion potential and electrolyte absorption are depressed, but there is no corresponding decrease in glucose dependent voltage increments. Further studies are now in progress that should relate morphologic damage and transport properties of the mucosa. 
The enteric surface coat on absorptive epithelial cells which results from abdominal irradiation now appears to be a non-specific secretory response to stimulation. The stimulations which produce an enteric surface coat are (1) X-irradiation, (2) nitrogen mustard, (3) bile cannulation, (4) anesthetic agents, and (5) bacterial infection. The effectiveness of these insults decreases in the order in which they are listed. The location of this coat suggests that it may play a role in absorption.

\section{TOXICITY OF RADIOELEMENTS}

Factors Affecting the Toxicity and Metabolism of Radionuclides - M. F. Sullivan

Iodine-131 is being administered daily by gavage to lactating rats in order to follow the passage of that radionuclide through the milk into the young. This experiment is part of a series planned to correlate ${ }^{13}{ }^{I}$ carcinogenicity with age.

Preliminary studies relating age and long-term isotope toxicity in guinea pigs has also begun. The relatively longer life span of guinea pigs suggests that this species is superior to rats for long-term studies.

\section{Plutonium-Americium Studies - R. W. Perkins}

The material Hastelloy-B has been found to be a suitable electrodeposition substrate for $\mathrm{Pu}$ and will be used in place of platinum in the electrodeposition studies. Several samples of tissue from animals which were exposed to plutonium from which $24 l_{\mathrm{Am}}$ grew in are presently being analyzed to determine the $239 \mathrm{Pu}:{ }^{24} 1_{\mathrm{Am}}$ ratio. The direct measurement of $24 \mathrm{I}_{\mathrm{Am}}$ and $239 \mathrm{Pu}$ in biological tissue ash is also being investigated. For the $300 \mathrm{~mm} \mathrm{Si}(\mathrm{Li})$ diode the $24 \mathrm{l}_{\text {Am }}$ counting efficiency is $0.25 \%$ (photon counts per alpha disintegration) and for $239 \mathrm{Pu}$ is less than $0.05 \%$ (photon counts per alpha disintegration). This relatively low counting efficiency limits the application of direct instrumental analysis to samples which contain relatively large amounts of $239 \mathrm{Pu}$ and $241_{\mathrm{Am}}$. The self-absorption of $239 \mathrm{Pu} X$ rays and the $241_{\mathrm{Am}}$ gamma ray in ashed biological materials is being determined so that the method can be applied to those samples for which it is applicable. 
Factors Affecting the Toxicity and Metabolism of Radionuclides in Aquatic Organisms - R. E. Nakatani

Experiments to determine whether tubifex can incorporate radionuclides bound to Columbia River sediments are completed and are undergoing final analysis. The retention of zinc in tubifex that have incorporated $65 \mathrm{zn}$ from water is strongly temperature and dose dependent. Autoradiographs of the worm show that the activity is distributed relatively uniformly through the soft internal tissues and is not localized in any particular organ. There is little, if any, ${ }^{65} \mathrm{Zn}$ bound to the integument.

It is commonly believed that tumors are rare in mollusks and a review of the literature tends to support this belief. our previous report of 14 tumors observed in four freshwater mussels out of 150 collected downstream from Hanford reactors has attracted considerable attention from other pathologists. Unfortunately, we have not been able to locate a similar population of freshwater mussels (Anodonta californiensis) upstream from Hanford to compare. However, 125 freshwater mussels (Margaritana margaritifera) were taken from the ozette River and examined for tumors. Three small polypoid growths were found on the foot of three different animals. Approximately one-fourth of the animals had watery cysts, approximately $10 \mathrm{~mm}$ in diameter, on the foot. The cause of these lesions is unknown, but they will be examined histologically in an attempt to determine their cause. Comparsion will be made to similar polypoid growths on the foot of freshwater mussels collected in the Columbia River. Our data to date suggest that tumors may not actually be as rare in mollusks as the literature might indicate.

\section{Effects of Radiostrontium in Miniature Swine - W. J. Clarke}

To date, 50 pigs (7.5\% of the total on experiment) have developed hemic or lymphatic disorders following the daily ingestion of ${ }^{90} \mathrm{Sr}$. Thirty-two of these cases have been myeloproliferative and 18 lymphoproliferative. Typically, the animals developing myelogenous leukemia have shown chronic alterations of their hemograms, consisting of decreased hematocrit, hemoglobin and platelets, and a gradual increase in numbers of reticulocytes and granulocytes. Contrary to these findings, only two of the animals with generalized lymphoproliferation have shown elevated leukocyte counts. Otherwise, their hemograms have appeared relatively normal. 
of particular interest this month has been the appearance of a "variant" in an animal classified as having a lymphogenous disorder. In this pig, there was a diffuse proliferation of plasma cells and plasmablasts in the lymph nodes, spleen, liver, and kidneys. The serum immunoglobulin values in this animal also gradually increased from a normal of 10-12\% to over $40 \%$ at the terminal bleeding.

In the six swine started on a short-term study-in-depth of the biological effects of the daily ingestion of $625 \mu \mathrm{Ci}$ $90 S_{r}$, no gross physical effects have been observed. However, one animal shows a slight but definite indication of coarsened trabeculation of the anterior mandible on its radiographs.

Three hundred mice have been injected with either lymphoproliferative or myelogenous leukemia $250 \mathrm{~m} \mu$ filtrates. One hundred mice are serving as controls. These animals will be observed for possible cell-free transmission of our ${ }^{90} \mathrm{Sr}-$ induced myelo-lymphoproliferative disorders.

$$
\text { Inhalation Studies - W. J. Bair }
$$

A preliminary experiment was completed to test for heterophile antibody formation capacity in rats following inhalation of ${ }^{239} \mathrm{PuO}_{2}$. The lung burden of these animals ranged from 0.04 to $1.0 \mu \mathrm{Ci}$. In comparison with the controls there was a general decline in heterophile antibodies through the seven weeks of observation. This reduction in antibody forming capacity was not necessarily correlated with either the lymphopenia which developed in the rats or the amount of plutonium in the lungs. The experiment will be repeated at higher plutonium doses.

In studies of the phagocytosis of $239 \mathrm{PuO}_{2}$ particles, it was found that the simultaneous intraperitoneal administration of 0.5 mMole Ca++ with $239 \mathrm{PuO}_{2}$ resulted in $90 \%$ of the plutonium being associated with gastrointestinal tissues within 15 minutes, compared with only about $15 \%$ when $239 \mathrm{PuO}_{2}$ alone was administered. The plutonium, $80 \%$ of which was in the mesenteries, could not be removed by saline or saline plus DTPA washing. These results are interesting, not only with respect to the role of phagocytosis and other mechanisms in transporting foreign particles, but also for possible contributions toward developing therapeutic procedures for removing plutonium particles. 
Al1 11 surviving dogs exposed 2-5 years ago to either $144 \mathrm{CeO}_{2}$ or ${ }^{106} \mathrm{RuO}_{2}$ were sacrificed for tissue analysis and histopathology.

\section{Space Nuclear Systems Studies - R. C. Thompson}

Two dogs were sacrificed immediately after exposure to $50 \mu \mathrm{PuO}_{2}$ microspheres. Gross scanning showed large deposits of $238 \mathrm{Pu}$ in the nasopharynx, esophagus, and stomach. The lungs have been thin sectioned for autoradiography.

Six dogs were exposed to aerosols of crushed $238 \mathrm{PuO}_{2}$ microspheres. The body burdens were approximately 20-100 $\mu \mathrm{Ci}$ after one week. Lymphopenia and loss of appetite are developing 2-3 weeks postexposure.

\section{Biological Systems Model Development - R. D. Benham}

The lung model has now been hybridized, i.e., adapted to combined use of analog plus digital computers, so that it can be used to predict the initial burden using excretion and body burden data from the standard (Dog 2) digital program used for al1 our dog experiments. The Dog 2 program digital printout is typed into the digital computer's keyboard. The digital computer converts the input data from microcuries to percent of initial body burden. Then the analog computer calculates the fecal and total body burden as a function of time. The analog program will adjust the initial deposition of the deep pulmonary lung compartment's fast component and the initial deposition of the pulmonary compartment's slow component until the best fit of the analog computer generated curves is made to the digital computer curves.

Work continued on the development of a hybrid program that will describe the movement of $65 \mathrm{zn}$ in the limpet snail.

Excretion Rates vs. Lung Burdens in Man - C. E. Newton, Jr. and W. J. Bair

A small foil of uranium-235 was shipped to the Lawrence Radiation Laboratory for irradiation with alpha particles in their cyclotron. It is expected that successful irradiation and separation will provide enough $237 \mathrm{Pu}$ to evaluate measurement capabilities prior to use in animal studies. The study 
of plutonium fluoride in dogs was expanded to include study of the effects of DTPA treatment in dogs exposed to plutonium fluoride.

\section{MOLECULAR AND CELLULAR LEVEL STUDIES}

\section{Cellular Regulatory Mechanisms - W. H. Matchett}

Cells of E. Coli were treated with chloramphenicol for various periods of time in the presence and absence of phosphate. Under these conditions, cells in the presence of phosphate will continue the synthesis of RNA in a linear fashion for many minutes. Cells in the absence of phosphate will not synthesize RNA. Cells washed free of chloramphenicol were placed in recovery medium containing radioactive uracil and the incorporation of uracil into acid insoluble macromolecular materials was followed for 20 minutes. From the data an initial rate of RNA synthesis was calculated for each sample of cells. The longer the cells remain in chloramphenicol in the presence of phosphate, the lower was their initial rate of synthesis of RNA. Cells in the absence of phosphate do not lose their initial ability to synthesize RNA for at least 80 minutes. These results are those to be expected if ribosomal precursors are indeed active in the regulation of RNA synthesis.

Studies were continued on factors controlling the rate of tryptophan transport in Neurospora crassa. The internal pool of tryptophan appears to be independent of the external concentration between $7.4 \times 10^{-4} \mathrm{M}$ and $3.0 \times 10^{-3} \mathrm{M}$. This observation is a reflection of the extremely effective tryptophan accumulating system. In other experiments, cells shifted from minimal medium to minimal medium containing tryptophan at $3 \times 10^{-3}$ Mapidly lost the capacity for tryptophan uptake. The loss of transport activity was time dependent. One-half the original activity was depleted five minutes after the shift and the loss in activity was maximal after 20 minutes. We may find that the residual activity of the tryptophan transport system is a measure of tryptophan reactivity with the transport system of another amino acid. 
Characterization of Radiation-Induced Free Radical Reactions in Agueous Systems - D. R. Kalkwarf

The stabilities of several radiation-induced radicals in concentrated aqueous sucrose solutions were investigated in order to determine the lifetimes of these species in environments that simulate portions of living tissue. Flavin mononucleotide, which forms a transient radical with a lifetime of several minutes in irradiated deaerated water at $\mathrm{pH} 6$, was found to form a radical which was stable for days in irradiated aqueous solutions containing $60 \%$ sucrose. No precautions for removing molecular oxygen were found necessary since the reaction of the radicals with oxygen was also found to be much slower in this medium. Similar behavior was exhibited by radicals derived from methylene blue during irradiation. In contrast, Wursters Blue radicals formed by the oxidation of $\mathrm{N}, \mathrm{N}, \mathrm{N}^{\prime}, \mathrm{N}^{\prime}$-tetramethylphenylenediamine in irradiated aqueous solutions, were found to be less stable in concentrated sucrose solutions. This difference in the effect of sucrose was attributed to reactions of molecular oxygen in air-oxidation of the radicals derived from flavin mononucleotide and methylene blue. Disproportionation is the predominant decay process for Wursters Blue radicals in aqueous solutions and, in this case, air-oxidation of the diamine productof this reaction replenishes the concentration of the radical.

\section{ENVIRONMENTAL RADIATION STUDIES}

\section{Eskimo Food Chain Studies - R. E. Nakatani}

Compilation of data and radioanalysis of lichen and caribou continued. Preparations were made for whole-body counting of residents of the three Alaskan villages during late April and early May. This will be the fifth and final trip to Alaska for FY 1967.

\section{Terrestrial Ecology - R. E. Nakatani}

Strontium-90 derived from worldwide fallout was measured in the forest floor litter of forest stands representative of major forest types in the Cascade Mountains. Stands west of the mountain summit had higher concentrations of $90 \mathrm{Sr}$ than did stands east of the summit. The highest values ( $13 \mathrm{pCi} / \mathrm{g})$ 
were recorded in a cedar-hemlock stand near Packwood and the lowest $(4 \mathrm{pCi} / \mathrm{g})$ were recorded in a Ponderosa pine stand near Tieton Ranger station. A similar distribution was reported for $137 \mathrm{Cs}$, although ${ }^{9}{ }^{0} \mathrm{Sr}$ values ranged between $4-5$ times lower than cesium values. As previously reported for $137 \mathrm{Cs}$, the $90 \mathrm{Sr}$ concentration of forest floor litter exceeds those of tree, shrub, and herb components of the same stand and points to the forest floor as an accumulation site for fallout derived radionuclides with long half-lives.

More data were gathered on the response of Perognathus parvus to gamma radiation. With the increase in sample sizes for intermediate dose levels there was a slight increase in the estimated LD 50/30; however, the increase was not statistically different from the former one. Both depilation and pocket eversion were observed again. Loss of hair was not as extensive as that seen during summer months, suggesting that the hair is more stable at this season, probably due to low follicular activity.

Sufficient Peromyscus maniculatus were captured and acclimated to colony conditions so that an experiment testing the effects of lowered dose rate was started. Trapping was begun on the 4 hectare study area and trapping success has been steady at $85 \%$. Ten species of native rodents were contributed to the Radiation Ecology Section, Oak Ridge National Laboratory. In return, we will get some preliminary hematological information, plus breeding stock of Peromyscus leucopus and oryzomys palustris. The latter species is of special interest to our work since it has a remarkably low resistance to radiation.

An exploratory analysis of some mathematical models applicable to the simplest uptake and retention process was completed. Efforts were principally directed toward the inclusion of realistic elements accounting for variability actually observed in the process. It was concluded that much of the variability associated with food chain passage of radionuclides may be due to significant differences between individuals (of the same species) in excretion rates. It was noted that as many as four distinct situations or processes may account for the failure of radionuclide retention data to plot as a straight line on a semi-logarithmic graph. 


\section{Plant Uptake of Radionuclides - F. P. Hungate}

Bromus tectorum (cheatgrass) was grown for approximately 100 days in $1 \mathrm{~kg}$ containers where the soil moisture was held constant by daily irrigations. The levels were 20, 18, 16, $14,12,9$, and $6 \%$ moisture on a dry-weight basis. There was little difference in growth or transpiration at the higher moisture levels. At moisture contents less than 15\% the plants were under stress. Cheatgrass can survive for a long period at moisture tensions in the 15 bar range. In this range cheatgrass can extract water from the soil and the transpiration rate is reduced only about 50\% whereas dry matter production is decreased many times. Root growth is reduced to $1 / 8$ and shoot growth to about $1 / 3$.

Mineral absorption and translocation to shoots are less dramatically affected and the effect varies with the ion. On a concentration basis, $\mathrm{K}, \mathrm{Ca}, \mathrm{Mg}$, and $\mathrm{Zn}$ are not influenced by soil moisture. Sodium, $\mathrm{Fe}$ and $\mathrm{Mn}$ concentrations in the shoots increase as the soil moisture tension increases; however, this increase is confounded with a decrease in growth. In general, the total amount of ions removed decreases with increasing tension except for $\mathrm{Na}$ and $\mathrm{Fe}$. Transport to the shoots is not directly related to transpiration.

\section{Columbia River Ecology - R. E. Nakatani}

Much of the month's effort was spent in processing and analyzing data collected during the past year. River sampling was conducted on a much-reduced scale with only plankton, caddis larvae, and juvenile fish being collected. Higher than usual river levels prevented collection of bottom organisms.

Laboratory experiment with the periphyton radionuclide uptake system continued. Results from $65 \mathrm{Zn}$ studies largely substantiated those from previous tests. Despite community type or age, the time to approximate equilibrium was similar, as was the activity accumulated on a weight basis. An approximately two-fold range of total $65 \mathrm{zn}$ accumulated is probably related to the greater biomass of the "young", spring communities with their mass of filamentous Ulothrix. Attempts are being made to explain the results obtained on the basis of known uptake and loss models. Both uptake and retention curves seem to be best described by a power-function model. 
The literature on effects of high temperatures on aquatic organisms has been reviewed and a document is being prepared on the subject. This review is needed for planning a more intensive, in situ, biological study on the Hanford thermal plumes.

\section{Temperature Effects on Metabolism of Aquatic Organisms} - R. E. Nakatani

Tubificid worms acclimated at 5,15 , and $25^{\circ} \mathrm{C}$ were tested for their upper lethal temperature limit. The lower the temperature of acclimation, the lower is the upper lethal limit. None of the worms survived for extended periods of time above $30^{\circ} \mathrm{C}$. It has not been possible to slowly acclimate the worms to higher temperatures and maintain them above $30^{\circ} \mathrm{C}$. However, they do very well at temperatures below $30^{\circ} \mathrm{C}$ in areas that have high levels of organic enrichment, and they can tolerate low oxygen tensions.

\section{Earth Sciences - W. A. Haney}

Geologic mapping between Wallula Gap and the Yakima Horn, the southeast end of the Rattlesnake Hills, disclosed that the line of buttes passing through Red Mountain, Badger Mountain, the Butte and intervening hills are elongated domes, rather than the dissected extension of the Rattlesnake Hills anticline. In all instances comparatively steep dips radiate outward from the domes whereas between domes dips are absent or are at low angles. Surface indications of faults are absent throughout most of the zone.

Domes imply vertical forces deforming the rocks rather than horizontal compressional forces classically ascribed to the formation of anticlines. The Horse Heaven Hills, in addition, are identified more as an uplifted and tilted plateau bordered by largely monoclinal folds rather than by simple asymmetrical anticlines.

The line of domes lies atop the Olympic-Wallowa Lineament, but the almost total lack of surface faulting and the change in nature of the structures at each end of the mapped zone, reinforces the concept that the lineament is a fortuitous association of topographic and structural features without a clear-cut common relationship. It is not a single major fault, fault zone or tectonic zone to which earthquakes can be related throughout its length. 
Several new programs were developed to ease problems in handling the great amount of data associated with analyzing large, complex ground water flow systems. The INTQ program integrates an equation, by Simpson's Rule formulated for unequal spacing, across a line of known permeabilities in either the constant $x$ or $y$ direction. The partial derivative is determined from a polynomial acquired from the fit of the region. The TRAVEL program integrates the travel time from graphical data picked from maps. Streamlines calculated in the STREAM program may be extended graphically in this manner. In the generation of streamlines, paths of flow are started from locations other than on the line of known permeabilities (base line). The permeabilities and travel time along a particular streamline are obtained by back-correcting with the permeability obtained from the crossing of the streamline and base line. The streamline data are accumulated on magnetic tape which simplifies plotting and card handling.

\section{ATMOSPHERIC RADIOACTIVITY AND FALLOUT}

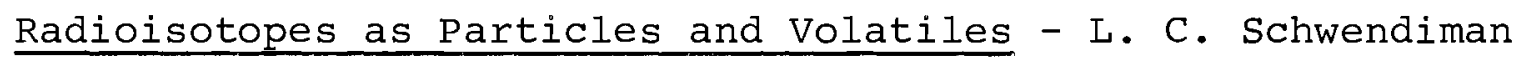

Turbulent Deposition in Vertical Tubes (G. A. Sehmel). The flux of particles was measured at points across the diameter of a $1.15 \mathrm{in.}$. ID tube through which monodisperse particle were being transported at an average velocity corresponding to a Reynolds number of 4100 (3 cfm). In earlier studies and for a much higher Reynolds number $(23,800)$, the flux profile was approximately that of the anticipated velocity gradient for particles of a few microns. Larger particle sizes up to about $10 \mu$ showed an increased flux near the wall. For still larger particles, the flux profile flattened significantly until the region near the wall was transporting only 10 \% more than an equal area near the tube axis.

With a much lower Reynolds number in the current experiments, particles smaller than $5 \mu$ in diameter were found in concentrations across the tube diameter about that expected from the velocity profile. In a region 0.2 in. from the wall the particles passing per unit cross sectional area were about 0.85 those passing in an equal area at the center of the tube. As particle size was increased from 5 to $9 \mu$, the flux profile flattened, then showed an inverse relation, the flux 
near the wall showing about $6 \%$ greater than at the center. An apparent critical particle size is reached at around $10 \mu$, since for particles of this size the flux profile again shows fewer particles moving near the wall than in the center core. As particle size is increased to $26 \mu$ significant preferential loading near the wall occurs, measurements showing about $30 \%$ more particles transported per unit area near the wall than in the center of the tube. These changes in flux profiles have not been explained theoretically, yet they are believed to be the consequence of the interplay of velocity profiles, particle deposition, rebounding and reentrainment, which are each in turn functions of particle size and quality, and average velocity in the conduit.

Deposition velocities were measured for the above runs in each of two 12 ft long tubes butted tightly together. The exponential deposition model

$$
\frac{C}{C_{O}}=\exp \left(-\frac{4 K L}{V D}\right)
$$

was assumed. In this equation,

$$
\begin{aligned}
\mathrm{C}_{\mathrm{O}}= & \begin{array}{l}
\text { concentration of monodisperse particles entering } \\
\text { the tube section, }
\end{array} \\
\mathrm{C}= & \begin{array}{l}
\text { concentration of monodisperse particles leaving } \\
\text { the tube section, }
\end{array} \\
\mathrm{K}= & \text { deposition velocity, cm/sec, } \\
\mathrm{L}= & \text { length of section, } \\
\mathrm{D}= & \text { diameter of tube, and } \\
\mathrm{V}= & \text { average velocity in the tube. }
\end{aligned}
$$

The deposition velocity in the upper $12 \mathrm{ft}$ of tubing was invariably much less than in the initial 12 ft after allowing for entrance effects. When the upper $12 \mathrm{ft}$ of tubing was held in the center of a 3 in. diameter tube affording an annular passageway for air from the lower laboratory to pass upward, thereby tending to equalize temperatures throughout the $24 \mathrm{ft}$ 
of tubing, the deposition velocity in both sections was much more nearly the same although fractional deposition was still higher in the first section. The placing of the 3 in. tube required mounting spacers in the form of a rubber plug bored to fit the 1.15 in. ID tube. The effect of this mounting would have been to suppress vibration transmitted to the tube which may have occurred in the absence of the jacket of the 3 in. tube. It is unlikely that this difference in mounting would have alone caused the observed differences. Although the observed differences in deposition velocities are great between the two unshielded sections, the practical significance is not great since fractional deposition in all cases was less than 15\% in the $12 \mathrm{ft}$ section. The great difference observed in deposition velocity, however, needs explanation since it occurs with what appears to be only subtle changes in ambient conditions.

Aerosol Generation (A. K. Postma). With the instrument panel installed, the high speed spinning disc aerosol generator was virtually completed. In a limited number of definitive operational experiments it was shown that from 0.1 to $0.4 \%$ of the mass of generated particles would be represented by satellite particles--those particles much smaller than the primary particles.

\section{Atmospheric Tracer Development - R. W. Perkins}

Most of the design and much of the fabrication work was completed on the electronic control system for the Noble Gas Atmospheric Diffusion Monitoring System. Discriminators and preamplifiers which will receive the signal from 64 field detectors were designed and are being fabricated on printed circuit boards. The stepping generator which controls storage intervals in 64-channel groups of the computer memory was completed. Logic circuits are being designed for handling the signals from the 64 detectors and determining their proper storage in the computer memory.

\section{Radioactive Fallout Rates and Mechanisms - R. W. Perkins}

With the continuing reduction in worldwide fallout subsequent to the major nuclear testing in 1961 and 1962, the contribution from minute amounts of radionuclides released from the Hanford plant has interfered with the local measurement of 
radionuclides from the worldwide fallout. To circumvent this problem the large volume air sampling pump located near Richland, Washington, has been moved to the Pangborn Airfield at Wenatchee and is operating satisfactorily at that location. A high altitude sampling program was recently started to define the profile of natural and artificlal radionuclides and the chemical composition of the aerosol between ground level and the middle stratosphere. The initial measurements under this program have been very successful. Precise measures of the cosmic ray-produced radionuclide $24 \mathrm{Na}$ on air filters collected between 30,000 and 65,000 feet were made and some ${ }^{39} \mathrm{Cl}$ values were obtained in this altitude interval. These preliminary results indicate that sufficiently large air volumes could be sampled with a smaller aircraft such as the Battelle Queenair aircraft to permit the measurement of several short-lived cosmic ray-produced radionuclides at elevations of 15,000 to 30,000 feet. This is particularly important since their production rates at this elevation will be required for the planned detailed precipitation scavenging studies. The air filters collected in this high altitude program are also providing information on the distribution of nuclear weapons-produced radionuclides. Preliminary measurements of the trace elements collected on IPC filter papers during these high altitude flights indicate that a sufficient amount of several trace elements can be collected to allow their measurement in the presence of the background of trace elements contained in the filter paper. Of the 6 trace elements studied, most of them were present in 10 to 100 times larger amounts on the filters which have been used for high altitude air sampling than on blank filters which had gone through all of the handling and other treatment except having air passed through them. A comparison of the trace elements in IPC filter paper with those in a highly pure organic filter that was supplied to us for testing by the NCAR laboratory showed that the NCAR filter contained about $1 / 4$ to $1 / 2$ the amounts of several trace elements. Although this lower trace element concentration in the NCAR filters is desirable, the initial measurements indicate that the IPC filter paper will be sufficiently clean for collecting atmospheric aerosols for analysis.

In earlier studies during the dry season, the distribution of some 20 radionuclides was determined in most of the common vegetation, in water and sediment samples, in air filters, and in several animal organs. This survey was repeated during 
a rainy season on similar samples. The samples from this latter survey which are presently being analyzed contain large amounts of $140 \mathrm{Ba}$ and other relatively short-lived radionuclides from the December 7, 1966, Chinese nuclear detonation. These short-lived radionuclides will provide the short-term distribution of radionuclides through the ecosystem in contrast to the long-term distribution which is provided by the longlived radionuclides.

\section{Fallout Phenomenology - W. E. Davis}

Additional analysis was completed on the nuclear test shot, Smoky. Twelve hour trajectories were taken from a point near ground zero along the second, third, and fourth reported levels above the surface (reported in the Northern Hemisphere Data Tabulation). A movement to the south was indicated for the air mass associated with the lower portion of the stem (from the surface to 3000 meters, MSL) during approximately the first nine hours. A 180 degree wind shift after that time moved the cloud's lower portion back toward ground zero at speeds of one to two meters per second. Upper flow during the entire period was toward the east. Particle trajectories through this wind regime from various heights in the cloud indicate a separation of particle sizes. Deposition of larger particles was predominant in the north portion of the pattern, while smaller particle deposition predominated to the south along an eastward extending corridor. This result has been substantiated by ground sampling. On crossing the Sheep Mountains, 85 kilometers east of ground zero, into a different near-surface wind regime, the separation process is less clearly defined.

$$
\text { Precipitation Scavenging - D. I. Hagen }
$$

The theoretical prediction of washout coefficients requires considerable detail on characteristics of the precipitation and scavenged material. These characteristics include: the rainfall intensity and droplet size distribution; the composition, density, size distribution, and wettability of the scavenged material; and the electrical charges on both droplets and scavenged particles. Experimental results from the two Rimrock AgI scavenging tests conducted in rain suggest that comparisons of measured washout coefficients with theoretical calculations would be useful toward development of a general 
model. The size distribution of the generated AgI particles is under investigation as a first step in providing additional information for the theoretical evaluation. Preliminary results of electron microscope examination of several grids exposed near the AgI source indicate that most of the particles have sizes of a few hundred angstrom units, all particles being smaller than $500 \AA$.

Transport and Diffusion - J. W. Sloot and T. W. Hinds

Four combined elevated and ground source multi-tracer releases were made during the month, bringing the total to twelve. Three of these were in unstable conditions and one in stable condition. Time consuming fluorescein assay techniques have prevented evaluation beyond that previously reported.

Data gathered with the real time sampler (RTS) during previous wake studies indicate that peak-to-average concentration ratios observed in the lee of a bullding are large, as great as 32 for a 5 second sample in a 15 minute test. However, strictly comparable data from unobstructed point sources are not available since studies described in the literature were confined to a minimum sampling time of about one minute. Thus, to provide a baseline of data from an unobstructed point source with which the wake data may be compared, a small sampling coursewas built around the point source generator at the Hanford sampling grid. Sampling arcs at 30 and 50 meters were constructed for use with existing arcs at 100 and 200 meters. Samplers were placed at eight degree intervals on the inner two arcs and at four degrees on the outer arcs. Four tests have been run in the series to provide comparative data, of which the initial two were used to check out the course and techniques. The succeeding two currently are being analyzed.

Radioanalytical Procedure Development - R. W. Perkins

A tentative procedure was developed for the removal of ${ }^{24} \mathrm{Na}$ from neutron-activated tissue samples. Following irradiation the tissue sample is wet ashed in a mixture of nitric acid and hydrogen peroxide and finally taken to dryness with perchloric acid. This residue is dissolved in water and passed through a heated column $\left(60^{\circ} \mathrm{C}\right)$ containing a section of anionhydroxide resin followed by anion-carbonate resin. Results indicate that more than $99 \%$ of the sodium passes through the 
column while greater than $99 \%$ of most of the elements of interest which have been tested are held. Copper is an exception and a significant amount of this follows sodium through the resin bed.

\section{MARINE SCIENCES}

Physical Chemistry of Ocean Solutions - R. W. Perkins

By using a large-volume high-resolution germanium diode, the feasibility of measuring 9 trace elements instrumentally in neutron activated sea water was demonstrated. A neutron irradiated sample of sea water is allowed to stand for 4 to 6 weeks to allow the $24 \mathrm{Na}$ and $82 \mathrm{Br}$ to decay. From a single count on a large-volume high-resolution diode it is possible to detect 14 radionuclides from which 9 trace elements can be measured. It is estimated that with the proper irradiation time these trace elements could be measured from a 100 minute count on our presently available 20 cubic centimeter Ge(Li) diode. It also appears that a few other trace elements can be measured with a higher neutron exposure and with a somewhat earlier count.

\section{RADIOLOGICAL AND HEALTH PHYSICS}

\section{Whole Body Counting - Earl Palmer}

The plans and agreements with the University of Washington were firmed up for the cooperative studies in total body calcium measurements. A joint proposal was written for submission to the AEC in which Battelle's financial support will come directly from the AEC. This support is expected to begin July $1,1967$. The contribution and responsibility of both Battelle and the University of Washington were clearly outlined. A preliminary article on this work has been written for publication and will be co-authored by both institutions.

Work at the Van de Graaff and University of Washington cyclotron shows that doses as low as 16 mrad are sufficient to produce enough $13_{\mathrm{N}}$ and $28_{\mathrm{Al}}$ to measure accurately total body nitrogen and phosphorus. Also, the $14 \mathrm{MeV}$ neutrons give a significantly different spectrum in a tissue equivalent phantom than do the lower energy cyclotron neutrons. 
The results of an experiment at the Van de Graaff accelerator cast some doubt on the total body sodium results obtained by Anderson, et al., of England. Two gallons of water containing 35 grams of magnesium was irradiated simultaneously with two gallons of water containing 80 grams of sodium. The $24 \mathrm{Na}$ produced in the $\mathrm{Mg}$ solution from $\alpha(\mathrm{n}, \mathrm{p})$ reaction was $44 \%$ of that produced in the sodium solution. The 35 and 80 grams of $\mathrm{Na}$ are the estimated amounts present in a standard man. This indicates that the interference from $\mathrm{Mg}$ is very significant and a correction for this interference would cause their estimated total body sodium values to be even lower. It appears that their whole method needs to be re-evaluated and we may be able to obtain and present reliable data on total body sodium by using the cyclotron neutrons where most of the neutrons are below the $5 \mathrm{MeV}$ threshold for the $\mathrm{n}, \mathrm{p}$ reaction on magnesium.

A way has been found to compensate for the end effect errors in scanning-type whole body counters and we are applying this technique to the six-crystal system. The method slows down the scan at each end such that, neglecting absorption, a source gives exactly the same counting rate regardless of position in the volume normally occupied by a human. We have tested the method manually and hope to have it running automatically within two weeks.

$$
\text { Radiation Dosimetry - W. E. Wilson }
$$

A modification of the floating electrode design was tried for the two-inch counter. The gas gain along the wire can be modified by very small changes in the terminating electrode. Experiments are now in progress for determining the optimum electrode design. Dose distributions in LET were calculated from data taken with 0.75 and $1.0 \mathrm{MeV}$ neutrons on the two-inch counter (without grid). They agree favorably with theoretical distributions according to Boag and are, in fact, in better agreement than distributions obtained earlier with the Rossi type counter (4 inch, with grid). These results mean that when properly designed, the much simpler gridless counter will give as reliable data as the more complex (and troublesome) ones. The servo pressure control system has been tested on the $\mathrm{dE} / \mathrm{dX}$ chamber and can hold it to \pm 0.04 torr. A portable version 
will be built with the gas and electronic components in a 30 in. high relay rack.

The shielded cave was completed and the absorbed dose calorimeter was installed and stabilized. Three measurements were made with the same ${ }^{60} \mathrm{Co}$ source measured before. Results of the present measurements are dose rates of $30.3,31.4$ and $32.5 \mathrm{rad} / \mathrm{hr}$ with an average of 31.4 . The dose rates recorded in January averaged $32.5 \mathrm{rad} / \mathrm{hr}$ which, when adjusted for the decay of 60 Co since January, becomes $31.5 \mathrm{rad} / \mathrm{hr}$. A discrepancy still exists between the dose rates measured calorimetrically and the tissue equivalent corrected dose rate (26.1) measured with a calibrated ion chamber. A major portion of this discrepancy may be due to in-scattering caused by the lead cave around the calorimeter. An experiment is under way to measure this scattering effect.

\section{RADIATION INSTRUMENTS}

\section{Radiological Chemistry - R. W. Perkins}

A $20 \mathrm{~cm}^{3}$ high-resolution germanium diode was evaluated for the measurement of trace elements in sea water following neutron activation. From a long count of the sea water sample, it was possible to identify 14 radionuclides from which the concentrations of the 9 trace elements, $\mathrm{Ca}, \mathrm{Fe}, \mathrm{Co}, \mathrm{Zn}$, $\mathrm{Sr}, \mathrm{Rb}, \mathrm{Sb}, \mathrm{Cs}$ and $\mathrm{U}$ could be calculated with good precision. From these preliminary results, it was estimated that with the proper irradiation time these trace elements could be measured from a 100 minute count on this diode.

The application of high-resolution $\mathrm{Ge}(\mathrm{Li})$ counters to the analysis of mineral material following neutron activation $i_{s}$ being investigated. Preliminary results have shown that, in addition to the several trace elements with radioactive daughters which decay by emission of high energy gamma rays, about 25 photopeaks are present below $0.25 \mathrm{MeV}$. Most of these are due to rare earth elements and it appears that, on calibration of the instrument for the rare earths, several of these can be measured by direct counting techniques. A high background problem resulted for the Si(Li) detector because of large amounts of thorium in its beryllium window. This problem has been eliminated by replacement of the beryllium window with a thin aluminized Mylar window. 
The National Bureau of Standards rock samples $\mathrm{G} / \mathrm{l}$ and $\mathrm{W} / \mathrm{I}$ are being analyzed by neutron activation and instrumental analysis. Several irradiations have been made and the trace elements are being measured by multidimensional gamma-ray spectrometry and Ge(Li) gamma-ray spectrometry. Our cooperation in this program will allow a more sure comparison of results in our laboratory with those of other laboratories throughout the country.

It was pointed out by Dr. J. M. Aase, USPH, Arctic Health Research Center, that some of the Alaskan Eskimos who have an iron deficiency also appear to have a manganese deficiency as evidenced by bone deformation. A program was started to investigate this possible deficiency in which hair samples will be analyzed as a monitor in estimating the body deficiency of manganese. Hair has been shown to be a good indicator of body burdens of other trace elements and trace radionuclides. The initial phase of this study will involve comparing the trace element concentration of manganese and other elements in hair from the individuals being studied with that in hair from normal Eskimos and normal individuals from other areas.

\section{Film Dosimetry Calibration Laboratory Study - C. M. Unruh}

The film dosimeter performance criteria and their methods of application were developed. The performance criteria are a function of dose level within each radiation category. This feature provides for the most meaningful evaluation since the actual percent error in observed film dosimeter dose evaluation decreases as the dose levels increase. By adopting performance criteria that are a function of dose levels, performance tests at 60 mrads become as meaningful as tests at 1000 mrads.

The performance criteria in each radiation category are expressed as a simple equation. By changing a constant in the equation, the performance criteria can be properly adjusted to require improved performance should that be desired at a later date. 


\section{Radiation Detection and Measurement Instruments - w. G. Spear}

Completion of a bench model of the improved animal physiological function transmitter prepares the system for extensive environmental and functional testing. In addition to blood pressure, respiration and body temperature measurement capabilities, this system includes a radionuclide uptake monitoring channel which uses miniature GM tubes as implantable detectors. A transmitter temperature monitoring capability is included to achieve the corrections necessary to obtain blood pressure data accurate to within $\pm 3 \mathrm{~mm} \mathrm{Hg}$. Incorporation of supply voltage regulation assures accurate system operation in ambient temperatures from 10 to $60^{\circ} \mathrm{C}$. All subcarrier systems operate properly and are arranged to produce minimum cross-talk. However, the completed FM carrier oscillator and power amplifier must be tested as to frequency stability and power requirements.

Purchase of the capital equipment required for the experimental tidal volume air monitoring system moved forward with the completion of the final specifications. The circuit design work necessary to accommodate both inhalation and exhalation cycles is finished and incorporated into the system schematics. Versatility of the design is enhanced by incorporating changes necessary for the system to accept flow signals from the smoke inhalation masks of the automatic aerosol control unit. It is anticipated that the system will also fill the future needs of other specialized projects.

Removal of the thick, energy absorbing dead layer of the surface-contoured radiation detection diodes should materially improve capability for low energy photon detection applications. As the theoretical intrinsic efficiency for ${ }^{59} \mathrm{Fe}$ is approximately 60\%, results expected with the etched diodes should greatly exceed the $2.2 \%$ efficiency obtained previously. Current plans include evaluation with a variety of other low energy isotopes.

Modification of a computer program, compatible with the UNIVAC 1107 computer, now permits the calculation of theoretical $X$ rays and alpha particles expected from plutonium samples of various isotopic compositions. An additional program change facilitates the calculation of Maximum Permissible Body Burden 
(MPBB) for the same plutonium samples. The results of sample computations satisfactorily demonstrated the usefulness of the program.

Computation of the theoretical effect of varying tissue mass, plus that due to small amounts of surface contamination, on plutonium $x$-ray and gamma-ray counting efficiency resulted in some interesting determinations. Preliminary calculations consider a $10 \mathrm{~cm}$ slab of tissue containing a uniform distribution of plutonium over which various thicknesses of tissue are placed. Addition of one $\mathrm{cm}$ of tissue decreases the $\mathrm{X}$-ray count rate by $76 \%$ while the gamma-ray count rate decreases only by $32.5 \%$. For a small-area detector, surface contamination representing more than $0.001 \%$ of the internal activity directly under the active area causes a 25응 change in the plutonium $x$-ray count rate. Using the same detector, surface contamination greater than $0.01 \%$ yields only a 7\% count rate change from $24 \mathrm{l}_{\text {Am }}$ gamma $(60 \mathrm{keV})$ sources. Using a large-area detector, the attenuation effect of overlying tissue on 24 Am gamma rays is only slightly reduced while the plutonium $17 \mathrm{keV}$ X-ray count is not affected. On the other hand, surface contamination effects are reduced by an order of magnitude for both the $24 \mathrm{I}_{\mathrm{Am}}$ and $23{ }^{2} \mathrm{Pu}$.

Tests of a developmental low-noise preamplifier revealed a considerable degree of unforeseen noise which was not reduced by electronic filtering and circuit modifications. Improvements incorporated in specific portions of the solid state circuitry should materially enhance stability and insure a reduced noise level in the new unit.

Completion of the construction on a special treatment chamber now permits the reactivation of molecular sieves used as filters in high vacuum systems. By heating the sieves in the chamber under vacuum, absorbed moisture and gases are driven off, thus regenerating the units for reuse. Initial tests indicate achievement of successful operation.

Temperature testing of the experimental mixed-field neutron-gamma dose rate measurement instrument revealed an instability at reduced operating temperatures $\left(5^{\circ} \mathrm{C}\right)$. Component changes, made to correct the deficiency, should provide the stability required for operation over the lower temperature ranges. Reliable operation is required from 0 to $55^{\circ} \mathrm{C}$. 


\section{DISTRIBUTION}

Number of Copies

Argonne National Laboratory

J. Loeding

3

Division of Technical Information Extension

1

Douglas United Nuclear

C. D. Corbitt

1

General Electric Company, Richland

M. C. Leverett

1

Hanford Occupational Health Foundation

1

Isochem

R. E. Tomlinson

5

$\underline{\text { Richland Operations Office }}$

C. L. Robinson

H. H. Schipper

D. G. Williams

12

USAEC, Washington, D. C. Division of Biology and Medicine

N. F. Barr

H. D. Bruner

W. W. Burr

W. D. Claus

C. L. Dunham

C. W. Edington

J. Z. Holland

H. L. Hollister

J. S. Kirby-Smith (Univ. Notre Dame)

S. A. Lough

J. R. Totter

J. N. Wolfe 
F. W. Albaugh

W. J. Bair (2)

C. A. Bennett

J. J. Cadwell

W. J. Clarke (2)

F. G. Dawson

D. R. de Halas

R. F. Dickerson

W. L. Dotson

C. E. Elderkin

S. L. Fawcett

J. J. Fuquay

R. F. Foster

W. A. Haney

H. Harty

J. F. Honstead

F. P. Hungate

R. L. Junkins

D. R. Kalkwarf

A. R. Keene

H. A. Kornberg

H. V. Larson

W. H. Matchett (2)

R. E. Nakatani (3)

C. E. Newton, Jr.

J. M. Nielsen

R. F. Palmer (2)

J. I. Palotay (2)

H. M. Parker

R. S. Paul (3)

D. W. Pearce

R. W. Perkins

E. H. Phinney

W. D. Richmond

W. C. Roesch

P. T. Santilli

L. C. Schmid

I. C. Schwendiman

C. I. Simpson

R. J. Sorenson (3)

W. G. Spear

M. F. Sullivan (2) 
R. C. Thompson

C. R. Tipton, Jr.

C. M. Unruh

E. E. Voiland

W. E. Wilson

R. J. Wood

D. C. Worlton

Technical Information Files

Technical Publications (2) 